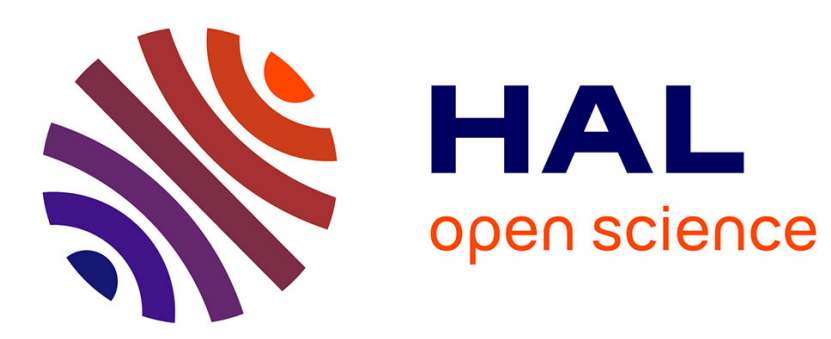

\title{
Low-Activation Energy Relaxations in Oxide Superconductors
}

G. Cannelli, R. Cantelli, F. Cordero, F. Trequattrini, M. Ferretti

\section{To cite this version:}

G. Cannelli, R. Cantelli, F. Cordero, F. Trequattrini, M. Ferretti. Low-Activation Energy Relaxations in Oxide Superconductors. Journal de Physique IV Proceedings, 1996, 06 (C8), pp.C8-469-C8-472. 10.1051/jp4:19968101 . jpa-00254529

\section{HAL Id: jpa-00254529 https://hal.science/jpa-00254529}

Submitted on 1 Jan 1996

HAL is a multi-disciplinary open access archive for the deposit and dissemination of scientific research documents, whether they are published or not. The documents may come from teaching and research institutions in France or abroad, or from public or private research centers.
L'archive ouverte pluridisciplinaire HAL, est destinée au dépôt et à la diffusion de documents scientifiques de niveau recherche, publiés ou non, émanant des établissements d'enseignement et de recherche français ou étrangers, des laboratoires publics ou privés. 


\title{
Low-Activation Energy Relaxations in Oxide Superconductors
}

\author{
G. Cannelli, R. Cantelli*, F. Cordero**, F. Trequattrini* and M. Ferretti*** \\ Università della Calabria, Dip. di Fisica, Arcavacata di Rende (CS), 87036, Italy \\ * Università di Roma "La Sapienza", Dip. di Fisica, P. le A. Moro, 00185 Roma, Italy \\ ** CNR, Istituto di Acustica "O.M. Corbino", Via Cassia 1216, 00189.Roma, Italy \\ *** Università di Genova, Dip. di Chimica e Chimica Industriale, Via Dodecanneso 31, 16146 Genova, \\ Italy
}

\begin{abstract}
A brief survey is made of the numerous anelastic relaxation processes with activation energies below $0.2 \mathrm{eV}$, which are found in the oxide superconductors with the 123 and 214 structure. Up to now there is no general agreement on their mechanisms, although some kind of electronic relaxation is often invoked. New measurements are presented of the process with the lowest activation energy, $\sim 80 \mathrm{meV}$, in superconducting $\mathrm{YBa}_{2} \mathrm{Cu}_{3} \mathrm{O}_{6+\mathrm{x}}$. It is shown that the intensity of this peak is maximum at the maximum oxygen stoichiometry, $\mathrm{x}$ $=1$, and steeply decreases in the restricted range $0.9<\mathrm{x}<1$, disappearing below it. It is proposed that the anelastic relaxation is caused by the reorientation of pairs of the $\mathrm{p}_{\mathrm{Z}}$ holes, which are observed at $x>0.8$ by $X$-ray absorption spectroscopy.
\end{abstract}

\section{INTRODUCTION}

The oxide superconductors, especially those with 123 and 214 structure, present several anelastic relaxation processes with activation energies unusually low for the oxides, but at the moment there is no general agreement on their mechanisms. For all of these processes some kind of electronic relaxation has been proposed; this seems an attractive possibility, in view of the uncommon electric properties of these oxides, but up to now no detailed mechanism or conclusive evidence has been found. In some cases it is not even ascertained whether these peaks are due to some intrinsic property of the material, or to impurities or imperfections not yet determined.

\section{LOW ACTIVATION ENERGY PEAKS AND POSSIBLE MECHANISMS}

In conducting and superconducting $\mathrm{YBa}_{2} \mathrm{Cu}_{3} \mathrm{O}_{6+x}$ three peaks are found with activation energies of $0.08,0.15$ and $0.2 \mathrm{eV}$ [1-5], which we label P1, P3 and P4, respectively. When the O stoichiometry is lowered below $\mathrm{x} \sim 0.3$, the material becomes superconducting, the above peaks disappear and a new one, P2, develops [6]. All the peaks in the conducting material have been shown to be affected by some cation substitution, which is regarded as a sign of the involvment electronic effects. For example, P3 and P4 seem to be affected by the partial substitution of $\mathrm{Y}^{3+}$ with $\mathrm{Ca}^{2+}[4]$, but also by the atmosphere in which the sample is sintered [5]. Peak P2 in the semiconducting material is the only one which approximates well a single Debye relaxation, and has also been detected with a completely different technique, as a peak of the NQR rate as function of temperature [7].

In $\mathrm{La}_{2-\mathrm{x}}(\mathrm{Sr} / \mathrm{Ba})_{\mathrm{X}} \mathrm{CuO}_{4+\mathrm{y}}$ a dissipation peak with an activation energy of $40-80 \mathrm{meV}$ has been found [8], whose intensity depends on $x$. The fact that the peak intensity is maximum when the superconducting critical temperature is maximum, suggests some connection between the peak and the holes [8]. 
The mechanisms which have been proposed to explain some of these processes include hopping of interstitial or off-centre atoms and the movement of dislocations or domain boundaries, besides electronic effects. The hopping of isolated $\mathrm{O}$ atoms in the nearly empty $\mathrm{CuO}_{\mathrm{x}}$ planes of $\mathrm{YBa}_{2} \mathrm{Cu}_{3} \mathrm{O}_{6+\mathrm{x}}$ can quantitatively explain peak P2 both in the acoustic [6] and NQR [7] experiments, but this is the only case in which a Snoek-like effect of a heavy atom can possibly require such a low activation energy. Indeed, it is also proposed that P2 is due to polaron hopping [7].

Regarding the hopping of off-centre atoms, the only case known in these oxides is that of the $O$ atoms in the $\mathrm{Cu}-\mathrm{O}$ chains in $\mathrm{YBa}_{2} \mathrm{Cu}_{3} \mathrm{O}_{6+x}[9,10]$, which could be responsible for $\mathrm{P} 4$ [1]. Other offcentre configurations can be supposed to occur in correspondence with some impurity or imperfection, which has not yet been detected by diffraction methods.

Finally, dislocations can hardly be considered, since they are far less abundant and mobile than in metals $[11,12]$.

\section{EXPERIMENTAL AND RESULTS}

The sample was a bar $\left(43 \times 4.3 \times 0.9 \mathrm{~mm}^{3}\right)$ of polycrystalline $\mathrm{YBa}_{2} \mathrm{Cu}_{3} \mathrm{O}_{6+\mathrm{x}}$, which was electrostatically excited on its 1 st and 5 th flexural modes $(1.7$ and $22 \mathrm{kHz}$ ). The starting material was oxygenated at $500{ }^{\circ} \mathrm{C}$ for few hours in flowing $\mathrm{O}_{2}$, and the oxygen content was estimated from the lattice parameters as $\mathrm{x}=6.93 \pm 0.03$. The superconducting transition had the midpoint at $90.3 \mathrm{~K}$ with a width of $1.3 \mathrm{~K}$ and zero resistance at $88 \mathrm{~K}$. We will refer to this state of the sample as to the $\mathrm{x}=0.93$ state. The accurate determination of the $\mathrm{O}$ stoichiometry requires the distruction of the sample, and therefore the values of $\mathrm{x}$ during the subsequent treatments are not known with high accuracy, but are deduced from the resistance curves and the pxT diagram of $\mathrm{YBa}_{2} \mathrm{Cu}_{3} \mathrm{O}_{6}+\mathrm{x}$.

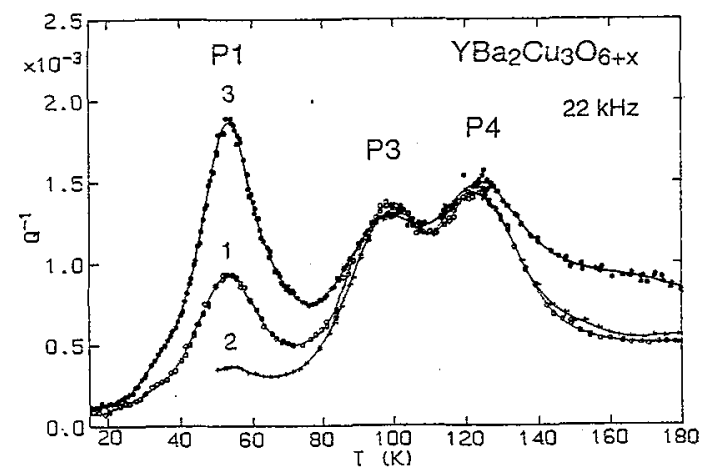

Figure 1: Elastic energy loss of $\mathrm{YBa}_{2} \mathrm{Cu}_{3} \mathrm{O}_{6+x}$ at three different stoichiometries $x \geq 0.9$. As prepared, $x \sim 0.93(1)$; after a vacuum anneal at $200^{\circ} \mathrm{C}, \mathrm{x} \sim 0.9(2)$; after a full oxygenation, $\mathrm{x} \sim 1(3)$.

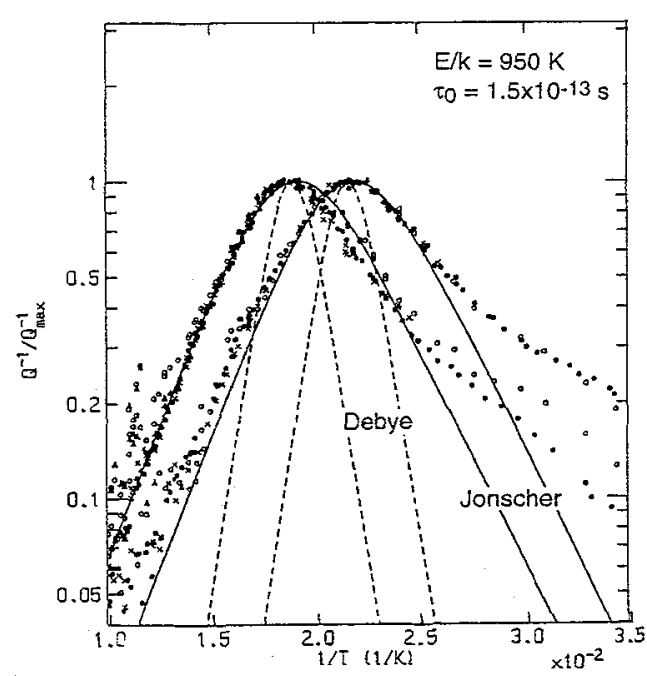

Figure 2: Normalized experimental data of peak P1 at 1.7 and $22 \mathrm{kHz}$ in the $\mathrm{x}=0.93$ and $\mathrm{x}=1$ states (same symbols as in Fig. 1), after subtraction of the background. The closed triangles are the difference between the experimental curves 2 and 1. For the dashed and continuos lines, see the text. 
The $\mathrm{Q}^{-1}(\mathrm{~T})$ curve in the initial state is labelled as 1 in Fig. 1, and it was stable over 6 years. The sample was then aged for 20 hours in a vacuum better than $10^{-5}$ mbar at $200^{\circ} \mathrm{C}$ and cooled to room temperature at $0.85 \mathrm{~K} / \mathrm{min}$. After this treatment, we estimate the $O$ contents as $x=0.90$ or higher. In fact, according to Ref. [13] a longer vacuum anneal at $320^{\circ} \mathrm{C}$ changes the $\mathrm{O}$ stoichiometry of ceramic samples from 0.94 to 0.90 . We measured again the electrical resistance, which showed $T_{C}=92.0 \mathrm{~K}$ and zero resistance at $89.6 \mathrm{~K}$. A slight increase and sharpening of the superconducting transition after a mild vacuum anneal was found also in [13] and may indicate that the sample was initially in the overdoped state. According to [14], the optimal doping is at $x=0.94$, which would imply that our sample passed from $x>0.94$ to $x \sim 0.94$; we will label this state as " $x=0.9$ ". After this slight reduction of $x$, the $Q^{-1}(T)$ curve remained unaffected, except for peak $P 1$ which was reduced by more than 3 times (curve 2).

The sample was again oxygenated in order to achieve a stoichiometry as close as possible to 1 (" $\mathrm{x}=1$ " state): it was heated up to $600^{\circ} \mathrm{C}$ in a UHV system with a quartz tube; then a static atmosphere of 1250 mbar $\mathrm{O}_{2}$ was admitted and the furnace was slowly cooled to room temperature at a rate of $-0.2 \mathrm{~K} / \mathrm{min}$. The cooling rate was reduced to $-0.1 \mathrm{~K} / \mathrm{min}$ between $490{ }^{\circ} \mathrm{C}$ and $300^{\circ} \mathrm{C}$, in order to maximize the $O$ uptake. The oxygenation raised the whole $Q^{-1}(T)$ (curve 3), but while P3 and P4 remained nearly unaffected, $P 1$ became more than twice higher than in the as prepared state $(x=0.93)$.

The reproducibility of the phenomenology was checked by observing the disappearance of $P 1$ after partially outgassing to $\mathrm{x} \sim 0.87$, and by observing the recovery of $\mathrm{P} 1$ to the maximum height after a full oxygenation.

Figure 2 shows the experimental data after subtraction of the background and of the contribution of the other two peaks, and after normalization of the intensities. The peak is much broader than a single Debye relaxation (shown as a dashed line), but its shape and temperature do not change with the intensity. This fact is unusual, since normally the shapes and temperatures of very broad peaks are scarcely reproducible. We also made a check of the consistency of the background subtraction, using as a background the experimental curve 1 , where $\mathrm{P} 1$ is small. These are the closed triangles, and fall exactly on the same curves as the others. It is possible to fit P1 with the expression first proposed by Jonscher for the dielectric relaxation of complex and correlated systems [15]:

$$
Q^{-1}=\Delta \frac{1}{(\omega \tau)^{-m}+(\omega \tau)^{1-n}}
$$

where $\tau(\mathrm{T})=\left(1.5 \times 10^{-13} \mathrm{~s}\right) \exp [(945 \mathrm{~K}) / \mathrm{T}]$. The Debye relaxation (dashed line) is obtained for $\mathrm{m}=1-\mathrm{n}$ $=1$, while the solid lines are obtained with $\mathrm{m}=0.41$ and $\mathrm{n}=0.67$.

\section{DISCUSSION}

The main characteristic of $\mathrm{P} 1$ is its strong dependence on $\mathrm{x}$ in an interval where most of the physical properties are nearly constant, and its disappearance below $\mathrm{x} \sim 0.9$. This fact excludes any relaxation of domain boundaries or geometrical defects, which certainly do not disappear below that stoichiometry; it is also difficult to imagine an off-centre occupation which is so sensitive to $\mathrm{x}$. We remain with the possibility of polaron relaxation.

A model for the distribution of the holes in $\mathrm{YBa}_{2} \mathrm{Cu}_{3} \mathrm{O}_{6+\mathrm{x}}$ as a function of $\mathrm{x}$ has been proposed by Tolentino et al. [16], based on spectroscopic observations of the characters of the holes. According to [16], the holes doped by the $\mathrm{O}$ atoms in the $\mathrm{CuO}_{\mathrm{x}}$ planes are distributed among the $2 \mathrm{p}_{\mathrm{x}}$ and $2 \mathrm{p}_{\mathrm{y}}$ orbitals of the $\mathrm{O}$ atoms in the $\mathrm{Cu}-\mathrm{O}$ chains and $\mathrm{CuO}_{2}$ planes. Increasing $\mathrm{x}$ above 0.8 , they observed that some holes start occupying also the $2 \mathrm{p}_{z}$ orbitals of the apical oxygens. These $\mathrm{p}_{z}$ holes seem the natural candidates for explaining P1, even though we do not know whether their mobility is compatible with an Arrhenius law with the activation energy of P1. The only problem is with their $z$ symmetry, which is the same as that of the lattice and therefore cannot cause anelastic relaxation. Such a problem can be solved by assuming that these holes may form pairs (bipolarons), whose reorientation requires an activation energy of $\sim 80 \mathrm{meV}$ and causes peak P1. This would also explain the very steep dependence of the intensity of $\mathrm{P} 1$ on $\mathrm{x}$, because the number of bipolarons would be roughly proportional to the square of the concentration of the $\mathrm{p}_{\mathrm{z}}$ holes.

It has been observed that the partial substitution of $\mathrm{Cu}$ with $\mathrm{Fe}$ suppresses $\mathrm{P} 1$ [2], while the partial substitution of $\mathrm{Y}$ with Pr progressively transforms P1 into another peak [3]. We do not know whether 
these observations are in contrast or confirm our model, since we are not aware of any study of the effects of the above substitutions on the $\mathrm{p}_{\mathrm{Z}}$ holes. We note, however, that great care must be taken that the substitutions do not affect also the $\mathrm{O}$ content, since $\mathrm{P} 1$ is extremely sensitive to it.

\section{CONCLUSION}

In the oxide superconductors several relaxation processes have been found with unusually low activation energies. An attractive and plausible explanation for many of them would be the hopping of polarons, but it has not yet been possible to find precise mechanisms or conclusive evidences of the involvment of polarons.

New measurements are presented of the peak with the lowest activation energy in superconducting $\mathrm{YBa}_{2} \mathrm{Cu}_{3} \mathrm{O}_{6+\mathrm{x}}$, and it is shown that it can be interpreted in terms of holes which have been observed by $\mathrm{X}$-ray spectroscopies. The peak develops itself only for $\mathrm{x}>0.9$, becoming maximum at $\mathrm{x}=1$. In this restricted range most of the physical properties are nearly constant, but XAS experiments revealed that the $p_{Z}$ orbitals of the apical oxygens start being occupied by holes. It is proposed that the dissipation peak is due to the reorientation of pairs of such holes.

\section{Acknowledgements}

The authors wish to thank L. Pitolli for his help in the preparation of the manuscript.

\section{REFERENCES}

1. G. Cannelli, R. Cantelli, F. Cordero, M. Ferretti, and L. Verdini, Phys. Rev. B 42, 7925 (1990).

2. M. Gazda, B. Kusz, R.J. Barczynski, L. Murawski, G. Gzowski, I. Davoli, and S. Stizza, Solid State Commun. 83, 793 (1992).

3. M. Gazda, B. Kusz, R.J. Barczynski, G. Gzowski, L. Murawski, and S. Stizza, J. Alloys and Compounds 211/212, 270 (1994).

4. M. Weller, Material Science Forum 119-121, 667 (1993).

5. G. Feusier, Y. Mi, and R. Schaller, Solid State Commun. 91, 591 (1994).

6. G. Cannelli, R. Cantelli, F. Cordero, M. Ferretti, Phys. Rev. B 38, 7200 (1988); G. Cannelli, R. Cantelli, F. Cordero, N. Piraccini, F. Trequattrini, and M. Ferretti, Phys. Rev. B 50, 16679 (1994).

7. S.G. Jang, C. Bucci, R. De Renzi, G. Guidi, M. Varotto, C. Segre, and P. Radaelli, Physica C 226, 301 (1994).

8. M. Gazda, B. Kusz, R.J. Barczynski, G. Gzowski, L. Murawski, I. Davoli and S. Stizza, Physica C 207, 300 (1993).

9. M. François, A. Junod, K. Yvon, A.W. Hewat, J.J. Capponi, P. Strobel, M. Marezio, and P. Fischer, Solid State Commun. 66, 1117 (1988).

10. W. Wong-Ng, F.W. Gayle, D.L. Kaiser, S.F. Watkins, and F.R. Fronczek, Phys. Rev. B 41, 4220 (1990).

11. S. Nakahara, S. Jin, R.C. Sherwood, and T.H. Tiefel, Appl. Phys. Lett. 54, 1926 (1989).

12. M. Jimenez-Melendo, A.R. de Arellano-Lopez, A. Dominguez-Rodriguez, K.C. Goretta, and J.L. Routbort, Acta metall. mater. 43, 2429 (1995).

13. C. Paris and M.P. Fontana, Il Nuovo Cimento 16D, 1843 (1994).

14. V. Breit, P. Schweiss, R. Hauff, H. Wühl, H. Claus, H. Rietschel, A. Erb, and G. Müller-Vogt, Phys. Rev. B 52, R15727 (1995).

15. A.K. Jonscher, Nature 256, 673 (1975).

16. H. Tolentino, F. Baudelet, A. Fontaine, T. Gourieux, G. Krill, J.Y. Henry, and J. Rossat-Mignod, Physica C 192, 115 (1992). 